\title{
Effect of Upstream Wake on Shower-Head Film Cooling
}

\author{
PING-HEI CHEN and JR-MING MIAO \\ Department of Mechanical Engineering, National Taiwan University, No. 1, Sec. 4, Roosevelt Rd., Taipei, Taiwan, R.O.C. \\ (Submitted to International Journal of Transport Phenomena)
}

\begin{abstract}
The present study aims to investigate the effect of an upstream wake on the convective transport phenomena over a turbine blade with shower-head film cooling. A naphthalene sublimation technique was implemented to obtain the detailed mass transfer distributions on both suction and pressure surfaces of the test blade. All mass transfer runs were conducted on a blowing-type wind tunnel with a six-blade linear cascade. The leading edge of the test blade was drilled with three rows of equally spaced injection holes. The upstream wake was simulated by a circular bar with the same diameter as that of the trailing edge of the test blade.

The test condition was fixed at $R e_{2}=397,000, M=0.8$, and $T u=0.4 \%$ and upstream wakes were generated at four different locations ahead of the blade cascade. Measured results show that there is a difference in mass transfer rate from the case without upstream wake. This difference is greater on the suction side than on the pressure side. The difference results from the interaction between the wake flow that is induced by the upstream wake and the injection flows that are ejected from the multi-rows of injection holes on the test blade. It was also found that the location of upstream wake generation significantly affects the mass transfer distributions on both surfaces of test blade.
\end{abstract}

Key Words: Film Cooling; Wake; Mass Transfer; Turbine Blade; Heat Transfer

\section{INTRODUCTION}

$\mathbf{T}$ The effects of shower-head film cooling and upstream wake on the turbine blade heat transfer and passage flow characteristics have been extensively studied in recent years. To date, measured results have been reported on the theory of wake-induced transition and unsteady heat transfer over the turbine blade area under the influence of passing wake and film cooling. Of particular interest for future studies are the complex flow field and heat transfer phenomena around the leading edge of the blade when the passing wake encounters the injection flows ejected through the injection holes. A knowledge of this complex flow structure resulting from the interaction of the passing wake and the laminar boundary-layer flow is essential to the reliable design of the modern turbine blade. In addition, measurements should be further extended to study the effect of such complex flow on the boundary-layer flow characteristics and heat transfer phenomena over the turbine blade surfaces.
A theory for wake-induced transition over a rotor blade was proposed by Mayle and Dullenkopf [1990]. They introduced a correlation, as evaluated from the measured heat transfer coefficients with Emmon's transition model, to predict the intermittency distribution over the wake-induced transition region. According to their correlation, the onset of wake-induced boundarylayer flow transition occurs much closer to the leading edge of the turbine blade than non-wake-induced boundary-layer flow transition because of an increase in the production of turbulent spots by the upstream wake.

Due to the natural complexity of the flow field within the blade passage, most prior experimental studies have focused on the measurements of heat transfer characteristics over the turbine blade surfaces for a system with either the injection flows or the upstream wake. On a circular cylinder, inferred as the leading edge of a turbine blade, Magari and LaGraff [1994] measured the stagnation heat transfer rate under the influence of an upstream wake. When the upstream wake was absent, the mass transfer distribution over a circular cylinder with injec- 
tion flows ejected from one row of injection holes was studied by Karni and Goldstein [1990] and Chen et al. [1994b].

Chen et al. [1994a] employed the naphthalene sublimation technique to investigate turbine blade mass transfer under the influence of an upstream wake, but without the presence of film cooling. The mass transfer distributions near the endwalls of a turbine blade with turbulent approaching boundary-layer flow was investigated by Goldstein et al. [1995] with the same mass transfer technique.

The combined effects of blowing ratio and mainstream turbulence level on turbine blade heat transfer and on turbine blade mass transfer for injection flows ejected from the multi-rows of injection holes located on the leadign edge of a turbine blade were respectively reported by Camci and Arts [1990] and Chen and Miao [1995]. A series of studies on heat transfer rate and film cooling effectiveness have been conducted by $\mathrm{Ou}$ and Han [1994], Ou et al. [1994], and Mehendale et al. [1994] which address the combined effects of upstream wake and blowing ratio. Their results indicate that the optimal blowing ratio for minimum blade surface heat load is 1.2 and 0.8 for $\mathrm{CO}_{2}$ and air injectants, respectively. However, their technique was not able to generate a spanwise distribution of the local heat transfer rate.

There are some studies (Dunn et al. [1989, 1994]; Abhari and Epstein [1994]) which were conducted in a short duration turbine test facility rather than in a low-speed wind tunnel with a linear cascade for simulating full engine conditions. Heat transfer data on an uncooled rotor blade coupled with an upstream cooled nozzle guiding vane were reported by Dunn et al. [1989]. Dunn et al. [1994] used the same experimental technique and equipment as above in a two-stage uncooled turbine to validate predictions based on a quasi-three dimensional numerical code that they developed. Abhari and Epstein [1994] performed their investigation on both fully cooled and uncooled rotating transonic turbine stages. The heat transfer rate over the suction surface is reduced by as much as 60 percent for the cooled blade, as indicated from their measured results.

Despite the numerous experimental studies performed on turbine blade heat or mass transfer under the influence of upstream passing wake and film cooling, few have addressed the spanwise variations of local heat or mass transfer in the downstream region of each injection hole. It can be argued that the variations will be large. In addition, the mass transfer over a first-stage rotor blade is expected to be time-dependent and periodic because over times different regions of the turbine blade are immersed in the upstream passing wake flow, which originates from the trailing edge of the upstream nozzle guiding vane. Accordingly, the turbine blade mass transfer distribution varies with the trace of the upstream passing wake. Of interest here are the combined effects of the upstream wake and the injection flows on local mass transfer over the blade surface. With respect to the upstream wake generation location, the variation of turbine blade mass transfer is also explored in the present study. Both spanwise-averaged and local mass transfer results are reported and discussed in detail. Experiments are conducted with the popular naphthalene sublimation technique.

\section{DESCRIPTION OF EXPERIMENT}

The present experimental apparatus consists of a wind tunnel, an injection flow system, and a test section with a scaled-up blade linear cascade. A schematic view of the experimental apparatus is shown in Figure 1. An automated data acquisition system was implemented to measure the surface profiles of the test blades that was originally coated with a layer of $1.5 \mathrm{~mm}$ solid naphthalene. The local naphthalene sublimation rate can be extracted from the measured surface profiles before and after test blade installation into the wind tunnel. Then, the local mass transfer rate can be evaluated from the measured naphthalene sublimation rate at the corresponding position.

The mainstream velocity can be easily varied by changing the rotating speed of the blower. The test section with the linear cascade, connected to the exit of convergent nozzle, has a dimension of $30 \mathrm{~cm}$ in width and $45 \mathrm{~cm}$ in height. At the end of the test section, the linear cascade has six scaled-up blades. The test blade is the fourth blade counted from the top of the linear cascade. The mainstream approaching velocity is measured by a pitot tube at a position of $100 \mathrm{~mm}$ upstream from the test blade leading edge. In addition, a slot is located at $60 \mathrm{~mm}$ downstream from the cascade in which a pitot tube is installed to measure the exit velocity of air flow.

A coating process was adopted for the preparation of a smooth exposed naphthalene surface with a span of 150 $\mathrm{mm}$ and a thickness of $1.5 \mathrm{~mm}$ on the test blade. A T-type thermocouple was embedded onto the naphthalene surface in order to evaluate the diffusion coefficient of naphthalene into air. A schematic view of the leading edge region of test blade was shown in Figure 2. The geometric data of the linear cascade are listed in Table I. In Figure $2, S_{s}$ and $S_{p}$ denote the curvilinearcoordinate along the suction and pressure sides, respectively. The centerlines of the three rows of injection holes are 


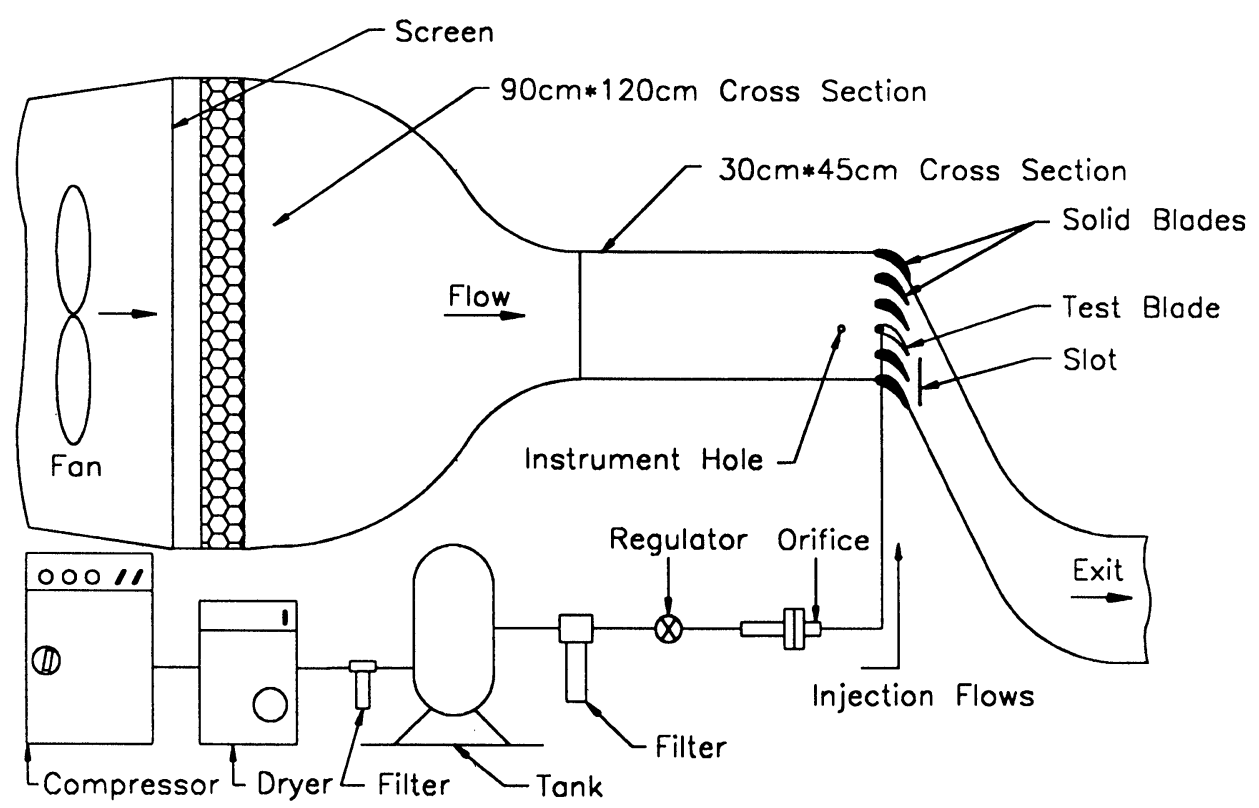

FIGURE 1 A schematic view of the experimental apparatus.

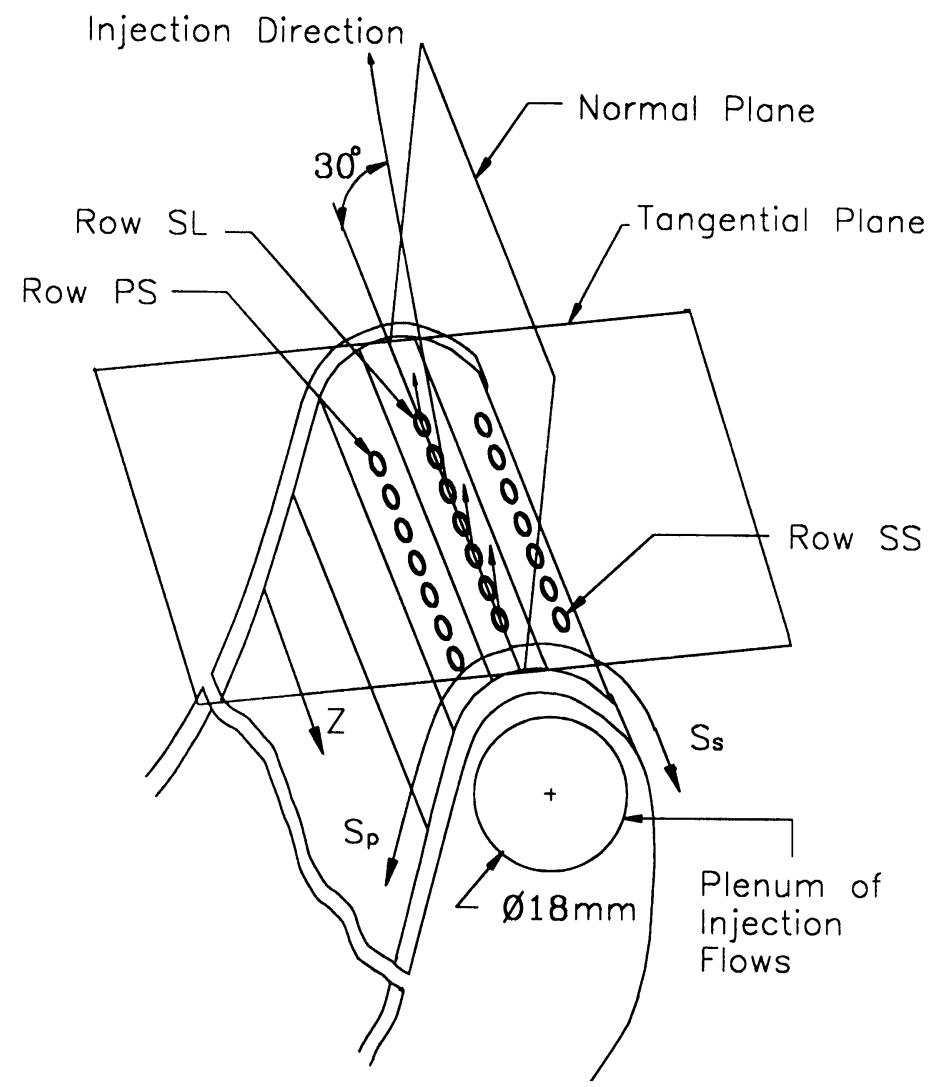

FIGURE 2 A schematic view of the s leading edge region of the test turbine blade. 
TABLE I

Geometric Data of Linear Cascade

\begin{tabular}{lc}
\hline Number of Blades & 6 \\
\hline Chord Length, $C$ & $152.1 \mathrm{~mm}$ \\
Axial Chord Length & $118.3 \mathrm{~mm}$ \\
Aspect Ratio & 1.972 \\
Pitch, $P$ & $90 \mathrm{~mm}$ \\
Inlet Flow Angle & $0^{\circ}$ \\
Exit Flow Angle & $63.8^{\circ}$ \\
Leading Edge Diameter & $23.2 \mathrm{~mm}$ \\
Trailing Edge Diameter, $d$ & $4.5 \mathrm{~mm}$ \\
\hline
\end{tabular}

located at the normalized distances of $S_{p} / S_{p f}=-0.088$ (denoted by the row $P S$ ), $S_{s} / S_{s f}=0.000$ (denoted by the row $S L$ ), and $S_{s} / S_{s f}=0.056$ (denoted by the row $S S$ ). The curvilinear distances at the trailing edge along the suction and pressure sides, denoted respectively by $S_{s f}$ and $S_{p f}$, are equal to $188 \mathrm{~mm}(\approx 1.236 C)$ and $154 \mathrm{~mm}(\approx$ $1.012 \mathrm{C}$ ). A staggered row arrangement is used in the multi-rows of injection holes. On each injection row, there are seven equally spaced injection holes, with a hole diameter of $3.33 \mathrm{~mm}$ and a pitch of $10 \mathrm{~mm}$. The injection angle to the test blade surface in the streamwise and spanwise directions are 90 degrees and 30 degrees, respectively. Because the test blade width $(176 \mathrm{~mm})$ is less than that of the test section $(300 \mathrm{~mm})$ the test blade with smooth naphthalene surfaces was first assembled to a supporting metal blade then carefully installed into the linear cascade.

To simulate an upstream wake a circular bar was installed at four separate locations upstream of the blade cascade, marked as A, B, C, and D, shown in Figure 3. The circular bar has a diameter of $4.5 \mathrm{~mm}$ which is the same as the diameter of trailing edge of test blade. For mass transfer results reported below, the tests denoted as wake $\mathrm{A}, \mathrm{B}, \mathrm{C}$, and $\mathrm{D}$ were conducted with the upstream wake generated at the corresponding locations. Between the cascade and the circular bar, $4 \mathrm{~cm}$ upstream from the cascade an instrumentation hole was located for inserting a hot-wire probe to measure the turbulence fluctuations between two adjacent blade passages. The turbulence level was measured by an IFA-100 constant temperature anemometer with a TSI model 1210-T1.5 hot-wire probe. In addition, the mainstream turbulence level was measured by the same hot-wire probe at a position of $10 \mathrm{~cm}$ upstream from the leading edge of the test blade for the case without the wake-generating circular.

The injection air flows were supplied by a screwedtype compressor. Since the injection flows may contain excessive water vapor after being compressed, a lowtemperature condenser was installed at the exit of com-

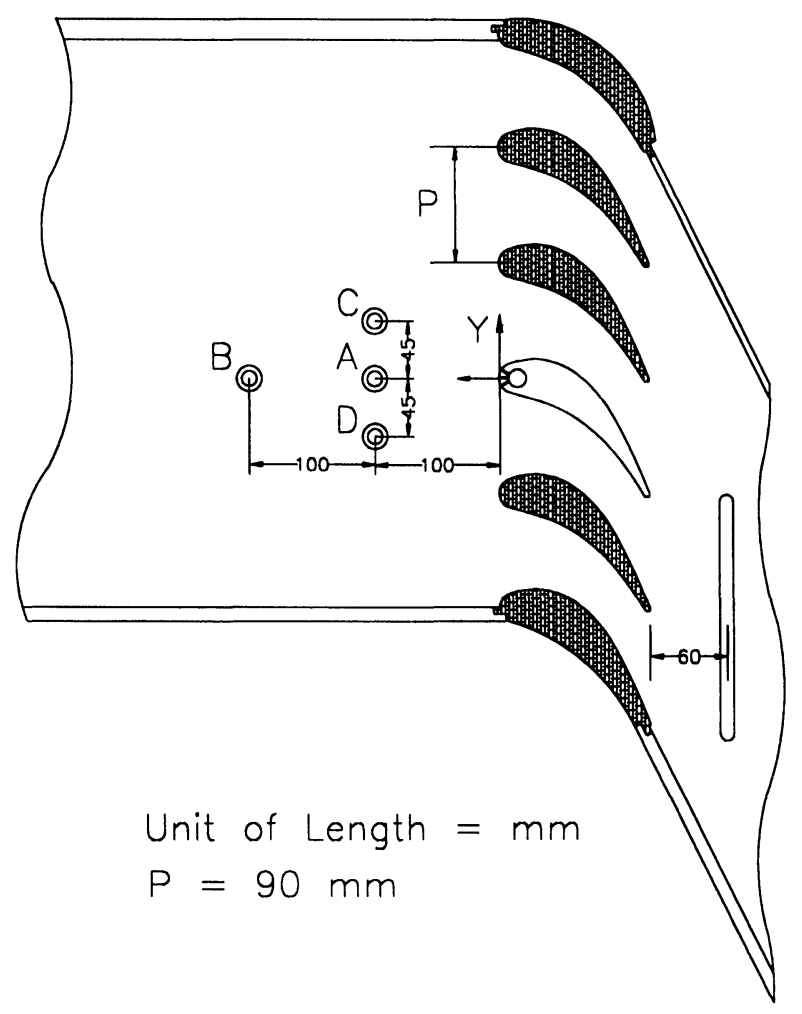

FIGURE 3 A schematic view of locations for installing wakegenerating cylinder.

pressor to eliminate water vapor in the injection flows. Downstream of the condenser, the injection flows were then heated to ambient temperature by a dryer. Further downstream, two air-filters were installed in the flow path to filter out droplets larger than $6 \mu \mathrm{m}$ and $1 \mu \mathrm{m}$, respectively. The volumetric flow rate of injection flows was measured by a calibrated flange-type orifice. Based on the measured volumetric flow rate and the air density upstream of the orifice, the mass flow rate of the injection flows was evaluated. Accordingly, the mass flux through the multi-rows of injection holes can be used to determine the blowing ratio, $M$, defined as

$$
M=\frac{\rho_{2} U_{2}}{\rho_{x} U_{x}}
$$

where $\rho_{2} U_{2}$ denotes the mass flux of injection flows, and $\rho_{\infty}$ and $U_{\infty}$ are the approaching mainstream air density and velocity, respectively.

In the naphthalene sublimation tests, the temperature difference between injection flows and mainstream should be kept at less than $0.2^{\circ} \mathrm{C}$. To achieve this temperature requirement, heated strips were wrapped 
around the upstream duct that was connected to the injection flow measurement orifice during the mass transfer run.

An automated data acquisition system was used to determine the sublimation depth of the coated naphthalene surface on the test blade after exposure to the mainstream in the wind tunnel. As shown in Figure 4, the automated data acquisition system consists of a four-axis positioning table coupled with four stepping motors, a linear variation differential transformer (LVDT) probe, four motor drivers, a gauge meter, a multimeter, and a Macintosh IIx computer. Details of the operating procedure and components for the data acquisition system can be found in Chen et al. [1994a,b]. The measured sublimation depth can be substituted into the following equation for determining the mass transfer coefficient, $h_{m}$,

$$
h_{m}=\frac{L_{s b} \rho_{s}}{\rho_{i: n} \Delta t}
$$

where $L_{s b}, \rho_{s}, \rho_{v, u}$, and $\Delta t$ denote the naphthalene sublimation depth, the solid naphthalene density, the naphthalene vapor density on the test blade surface, and the time duration for the exposure of test blade surface to the mainstream.

Generally, the local mass transfer rate can be expressed as the local Sherwood number, defined as

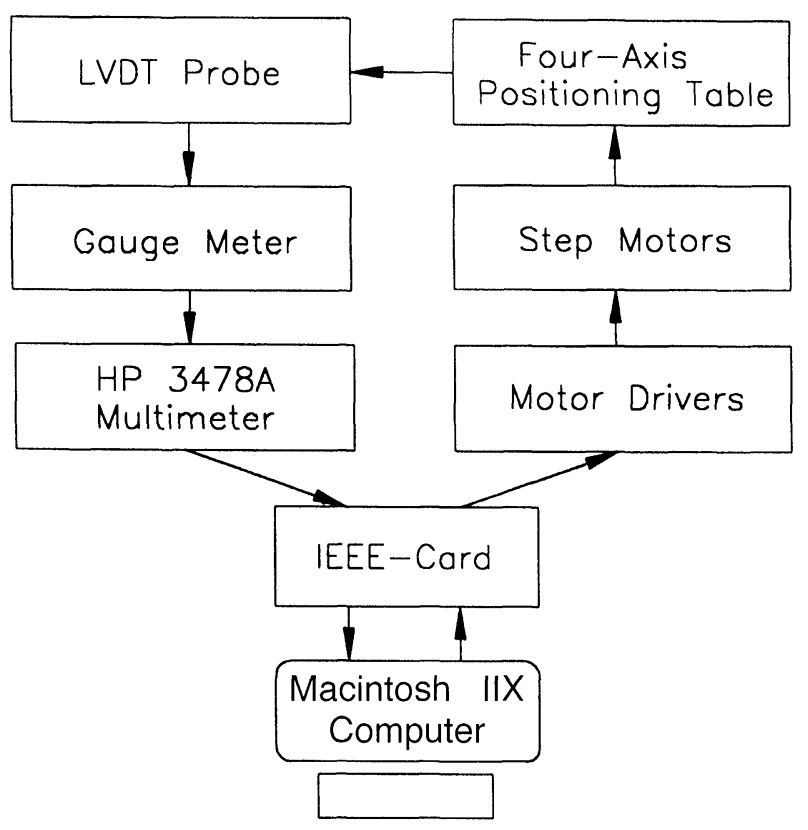

FIGURE 4 The automated data acquisition system.

$$
S h=\frac{h_{m} C}{D_{f}}
$$

where $C$ is the chord length of the test blade and $D_{f}$ is the diffusion coefficient of naphthalene into air. A correlation that relates the diffusion coefficient of naphthalene into air to temperature as well as pressure is given by Cho et al. [1994].

In all mass transfer runs, the blowing ratio is $M=0.8$, the mainstream turbulence level is $T u=0.4 \%$ and the exit Reynolds number is kept at $R e_{2}=397,000$. For each run, the sublimation depth of test blade naphthalene surface are measured at 74 streamwise locations along the blade surface; 39 on the suction side and 35 on the pressure side. At each streamwise location, the measured region spans from $Z=61 \mathrm{~mm}$ to $Z=97 \mathrm{~mm}$ with a spacing of $1.5 \mathrm{~mm}$. The position of $Z=0$ corresponds to the endwall. The local mass transfer results within the region whose span covers three neighboring injection holes from $Z=61 \mathrm{~mm}$ to $Z=91 \mathrm{~mm}$ are used to evaluate the spanwise-averaged Sherwood number $(\overline{S h})$. Based on the Kline and McClintock's [1953] equation at a confidence level of $95 \%$ yields resulting uncertainties for $M, R e_{2}$, and $S h$ of $5 \%, 0.5 \%$, and $6 \%$, respectively.

\section{RESULTS AND DISCUSSION}

\section{Pitchwise Turbulence Distribution in the Wake}

Figure 5 shows the turbulence level along the pitchwise direction measured at a location of $4 \mathrm{~cm}$ upstream from the linear cascade under the upstream wake conditions. Measured results indicate the highest turbulence level in the wake flow is as large as $15 \%$. The fact that the turbulence distribution for the case of wake $\mathrm{A}$ is much higher than that for the case of wake B suggests that the turbulence level in the wake flow falls sharply as the wake flow propagates downstream. Remember that the upstream wake for B originates only $10 \mathrm{~cm}$ upstream from that of case A. In all cases around the centerline location of the circular bar $(Y / P=0$ for the cases of wake $\mathrm{A}$ and $\mathrm{B})$, a symmetric distribution in the turbulence level can be observed.

\section{Spanwise-averaged Mass Transfer Results}

Figure 6 compares the present measured mass transfer results with those in prior studies on the test blades with the same geometric profile without the presence of shower-head film cooling or an upstream wake. The blow-up of mass transfer distributions over the leading 


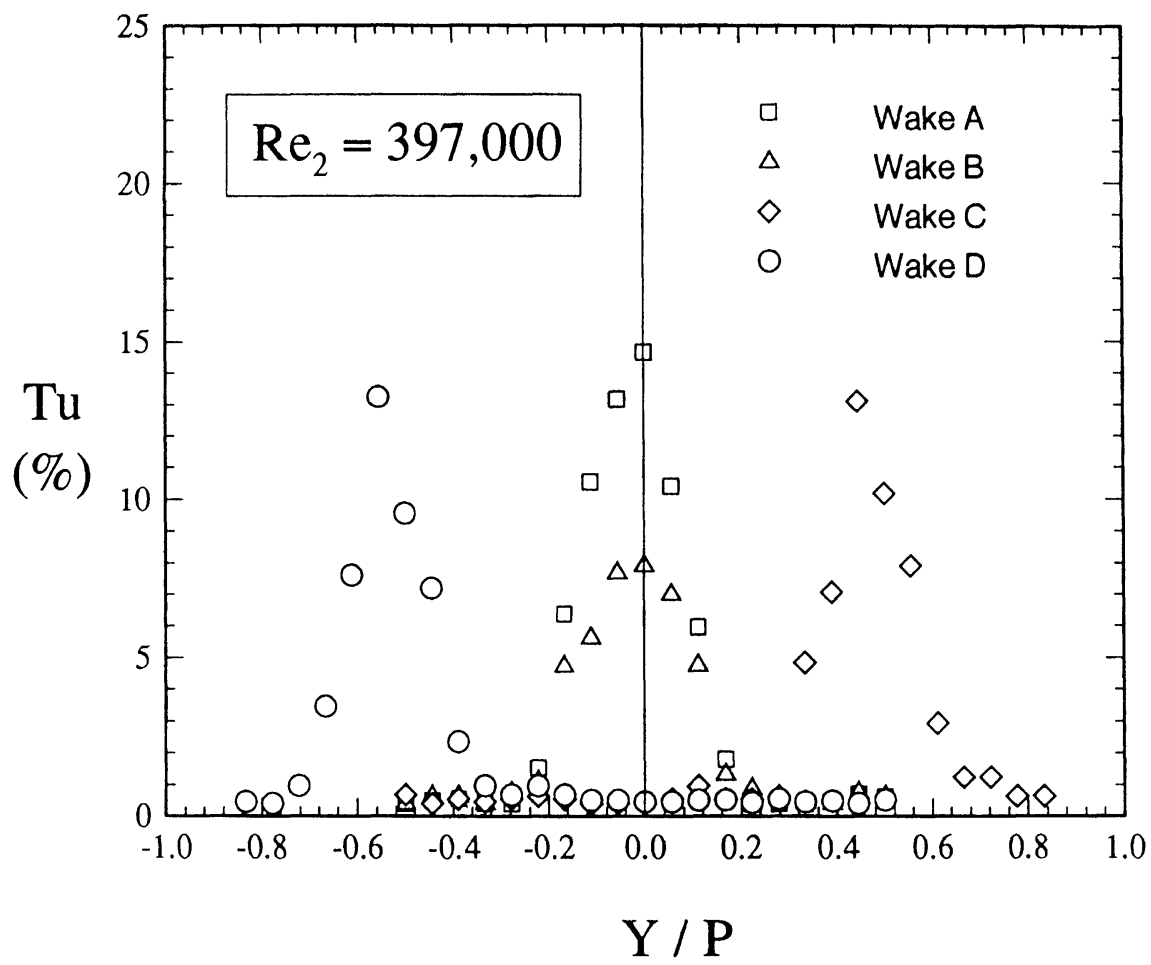

FIGURE 5 The turbulence level along the pitchwise direction at $4 \mathrm{~cm}$ upstream of the linear cascade under the upstream wake conditions.

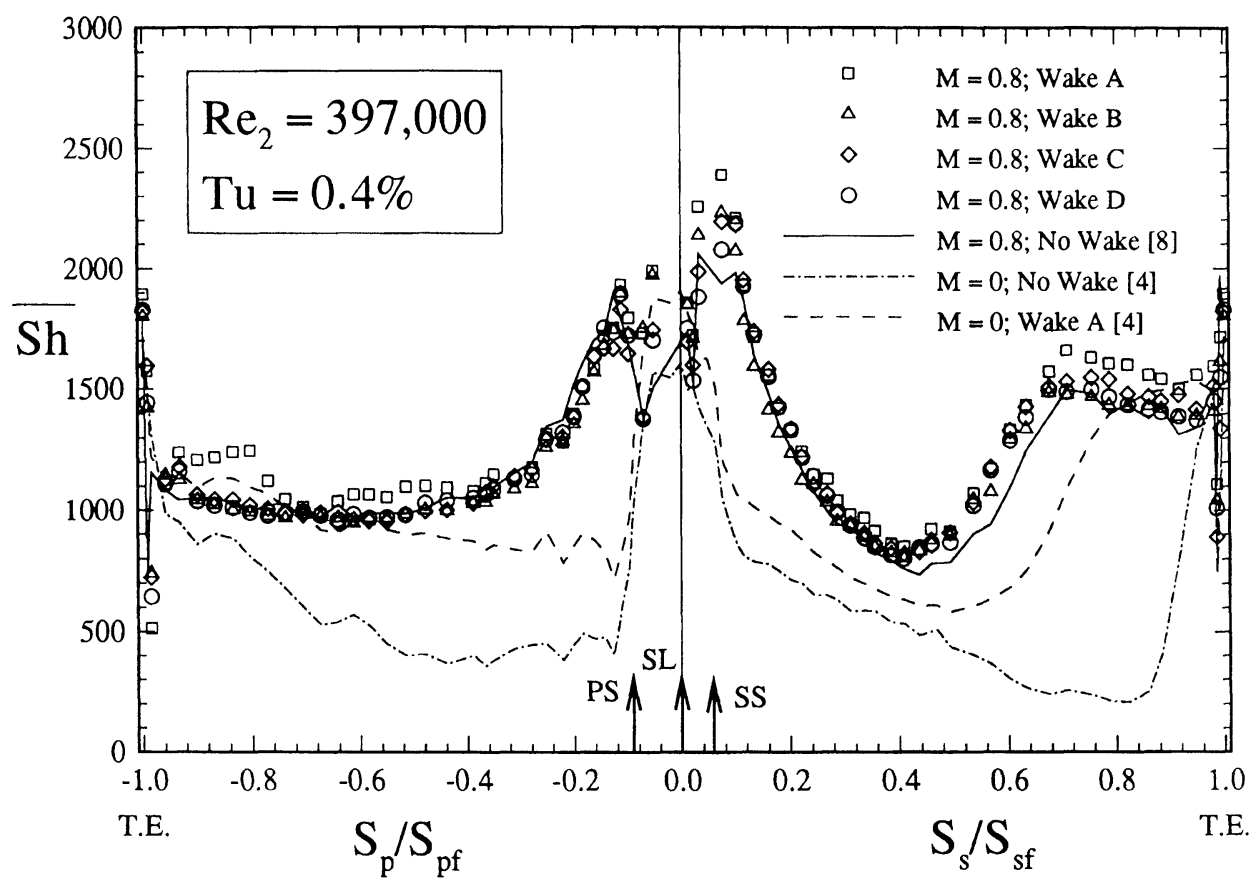

FIGURE 6 Influence of wake on the spanwise $\overline{S h}$ distributions over the both surfaces of the test blade for $T u=0.4 \%$ and $R e_{2}=397,000$. 
edge region between $S_{p} / S_{p f}=-0.2$ and $S_{s} / S_{s f}=0.2$ is shown in Figure 7 . On the horizontal axis, three arrows denote the centerline locations of the injection rows $S L$, $P S$, and SS. The three solid lines without symbols are the measured results given by Chen et al. [1994a] and Chen and Miao [1995]. The runs denoted with $M=0$ were conducted with no injection holes. The runs denoted with no wake were conducted without the presence of an upstream wake. Detailed discussion on the cause for such dramatic variation in the streamwise distributions of turbine blade mass transfer, as documented in Figures 6 and 7 , can be found in the aforementioned two papers.

Apparently, the injection flows have a more significant effect than the upstream wake on the turbine blade mass transfer. An upstream wake with the injection flows actually further enhances the turbine blade mass transfer, especially on the suction side.

In the region just downstream of the front stagnation line, a recirculated flow zone is expected to occur between injection rows $S L$ and $S S$ when the mainstream directly encounters the injection flows ejected from the injection row $S L$. The injection flows act as solid flow blocks which cause such a recirculated flow zone on the blade surface. Figure 7 shows a rise in the spanwise-averaged mass transfer rate for the cases of wake A-D $\left(S_{S}\right)$ $S_{s f}=0.033$ ) that is probably due to reattachment following separation of the mainstream. On the suction surface, maximum mass transfer is caused by the injection flows from the injection row SS. A sharp fall following the highest peak is probably associated with the growth of the laminar boundary-layer flow. The minimum value of $S h$ is at the transition from the laminar boundary-layer flow to turbulent flow. Beyond this transition point, there is a rise in the mass transfer distribution. After the boundarylayer flow becomes fully turbulent, a slow decline in mass transfer is observed. The large variation in curvature near the trailing edge of the blade results in the formation of a trailing-edge wake (so named to distinguish it from the upstream wake). This in turns leads to the extremely sharp variation in the spanwise-averaged mass transfer rate as observed in Figures 6 and 7. At the separation of the turbulent boundary-layer flow, the mass transfer rate reaches a local minimum. However, vortex shedding in the wake flow from the trailing edge of the blade significantly increases the mass transfer rate, so the mass transfer rate again reaches a peak whose value approaches that near the leading edge.

On the pressure surface, there are two peaks in the spanwise-averaged mass transfer distribution near the leading edge, as shown in Figure 7. These two peaks result from the injection flows from the rows of injection holes, SL and PS. Downstream from the injection row $P S$, the boundary-layer flow becomes fully turbulent. Consequently, the mass transfer rate monotonically decreases to a minimum at a streamwise position near $S_{p} / S_{p f} \approx-0.7$, as illustrated in Figure 6. Beyond this

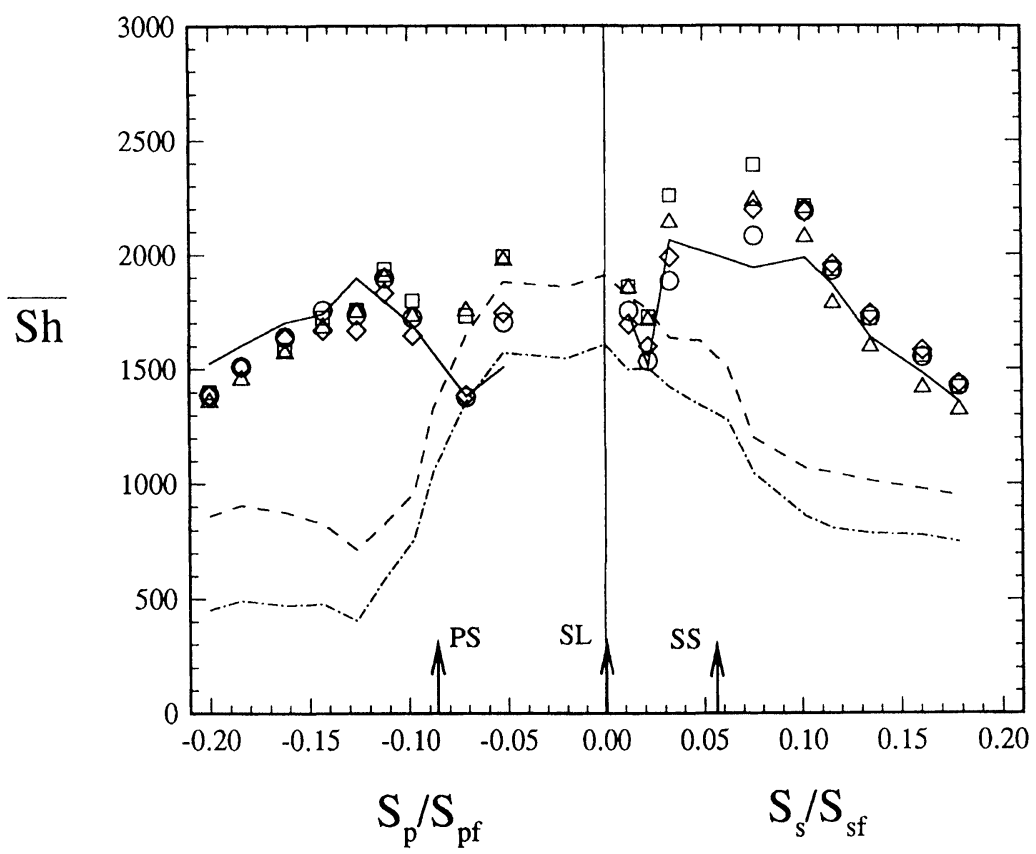

FIGURE 7 The blow-up of Sh distributions over the leading edge of the test blade. 
point, a slow increase in the mass transfer is observed, probably, due to the acceleration of the boundary-layer flow in this region. Near the trailing edge, the separation of boundary-layer flow and the vortex shedding in the wake flow result in a sharp variation in the streamwise distribution of $\overline{S h}$.

Despite variations in upstream wake generation location, the difference in mass transfer results among all four cases is insignificant except in the region just downstream of the injection holes, as observed in Figure 7. It is worth noting that although in cases of wake $C$ and $\mathrm{D}$ the flow characteristics are different, the mass transfer distributions are similar. For example in the case of wake $\mathrm{C}$, the wake flow travels downstream with the mainstream then enters into the flow passage between the suction surface of the test blade and the pressure surface of its neighboring blade. On the other hand, in the case of wake $\mathrm{D}$ the wake flow combines with the mainstream and moves into the flow passage where it is confined by the pressure side of the test blade and the suction side of its neighboring blade. One would expect that the case of wake $C$ would affect the turbine blade mass transfer more on the suction surface of the test blade but less on the pressure surface. However, this phenomena does not occur when the injection flows are ejected from the leading edge region of the blade. This is because the flow field in the blade passage is severely disturbed by the presence of injection flows therefore the promotion of the turbulence level by the upstream wake $\mathrm{C}$ becomes insignificant.

As shown in both Figures 6 and 7, the mass transfer rate for the case of wake $\mathrm{A}$ is highest among all four cases, probably because of the upstream wake turbulence level is the highest among the 5 cases experienced at the leading edge region of the test blade. A prior study [1994a] has already revealed that the position of the upstream wake significantly effects the mass transfer distributions on both surfaces of the test blade without film cooling. However, the present study shows that the mass transfer distributions are not strongly dependent on the position used to generate the upstream wake if the injection flows are ejected in the leading edge region, as indicated from Figure 7.

\section{Spanwise Distributions of Local Mass Transfer Rates}

Near the leading edge of the turbine blade, the spanwise distributions of $S h$ are expected to be periodic as a result of injection flows through multi-rows of injection holes. The measured results are presented to show the significance in the spanwise variation of the local mass transfer rate and the effect of upstream wake generation location on the local mass transfer rate. At $\operatorname{Re}_{2}=397,000, M=$ 0.8 , and $T u=0.4 \%$, Figures $8(\mathrm{a})-(\mathrm{f})$ show the spanwise distribution of the local Sherwood number on the suction surface of the blade at different curvilinear distances for all four runs (A-D). On the pressure side, local mass transfer results are presented in Figures 9(a)-(e). In the present study, injection flows are ejected towards the endwall where $Z=0$. There are groups of arrows on the horizontal axis in these Figures. These arrows are used to indicate the centerline and boundaries of each row of injection holes.

On the suction surface, the variation in the spanwise mass transfer distributions is notable and periodic, particularly in the region near the leading edge. The wavelength of the periodically spanwise mass transfer distribution corresponds to the pitch of the injection holes. At $S_{s} / S_{s f}=0.033$, the turbulence level in the wake encountered by the leading edge results in a difference in the measured mass transfer rate among these four cases. Downstream of the injection row $S S$, twin peaks in the local mass transfer at $S_{s} / S_{s f}=0.102$ appears at locations between two neighboring injection holes. This twin-peak appearance is probably due to the formation of a pair of counter-rotating vortices. Previous observation of these two vortices was reported by Chen and Miao [1995] and Kurse [1985]. As the injection jets move downstream, these two vortices quickly merge to become a single vortex, as indicated in Figure $8(\mathrm{~d})$ by a single peak in the local mass transfer rate at $S_{s} / S_{s f}=0.179$ between two neighboring holes. One can also notice that the peak in local mass transfer does not lie on the centerline of the injection holes. This is probably due to the injection flows ejected at $3^{\circ}$ degrees toward the endwall. Thus, the injection flows travel downstream, the peak shifts towards the endwall (Figures 8(d)-(e)). Additionally, the spanwise distribution of $S h$ is already quite uniform for runs of both wake A and B but it still sustains a distinctly periodic behavior for the other two cases at $S_{s} / S_{s f}=0.534$, as shown in Fig. 8(e). The periodic behavior in local mass transfer indicates the mixing between the injection jets and the boundary-layer flow on the suction surface is not completed yet. Figure 8(e) clearly illustrate the difference in the local mass transfer rate among various tests. However, Figure 6 shows almost the same spanwise-averaged value for $\overline{S h}$. At the location of $S_{s} / S_{s f}=0.823$, shown in Fig. 8(f), the uniform distribution in the local mass transfer rate for all runs indicates that the fully turbulent boundary-layer flow is completely mixed with the injection flows and has become two-dimensional in space.

On the pressure surface, the local mass transfer rate at $S_{p} / S_{p f}=-0.071$ which is the location just upstream from 


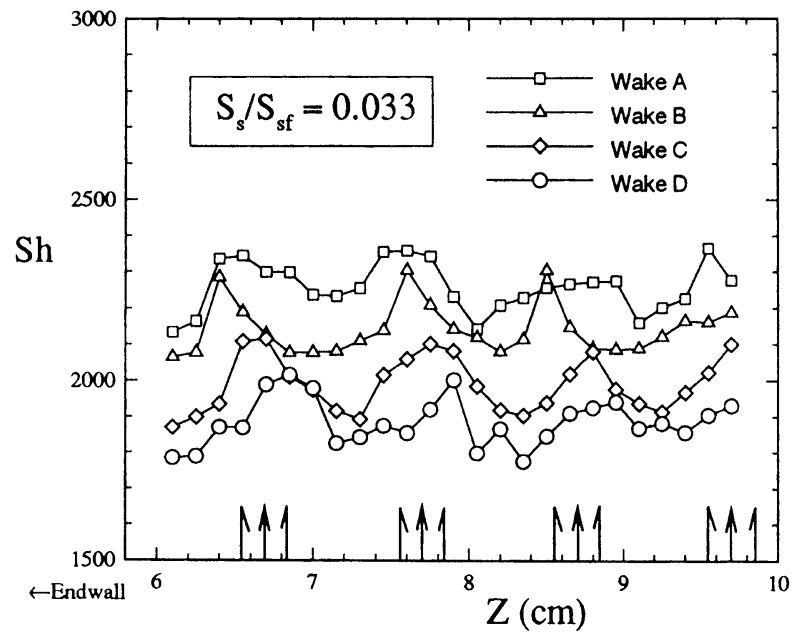

(a)

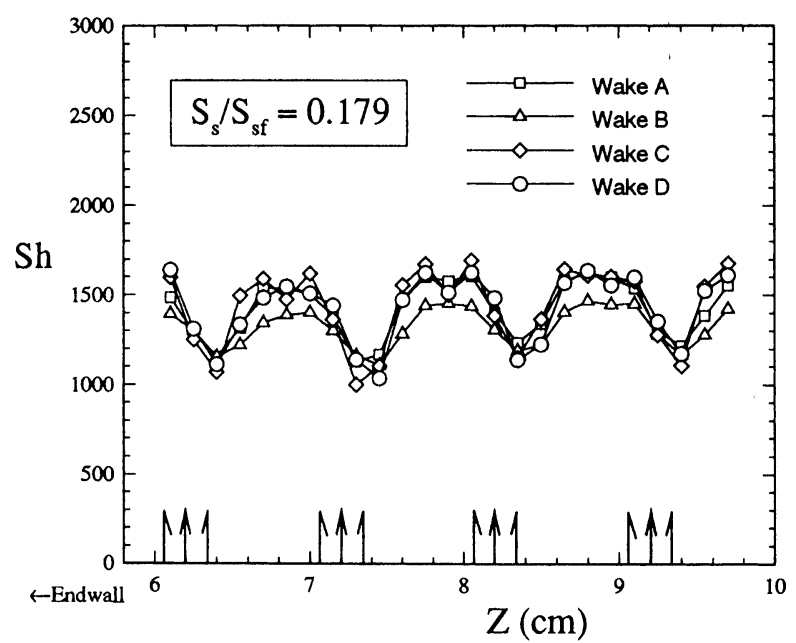

(c)

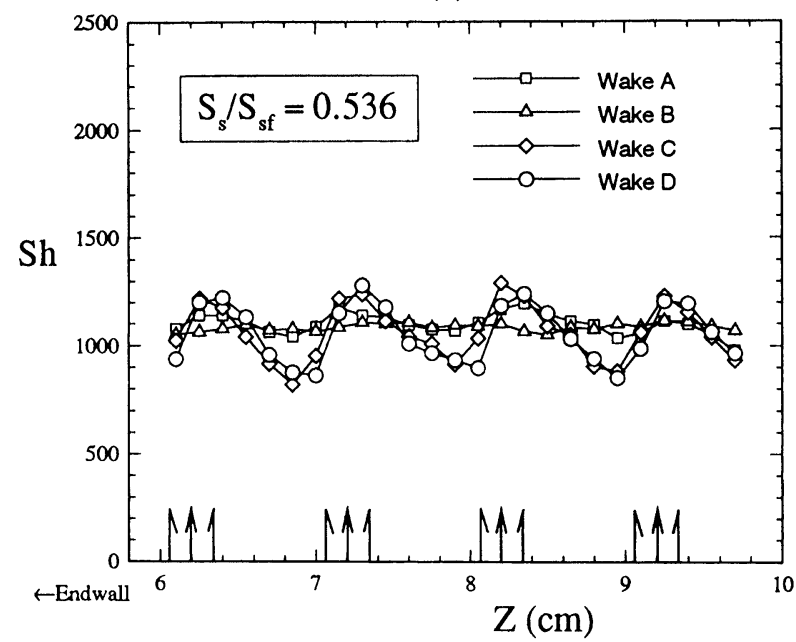

(e)

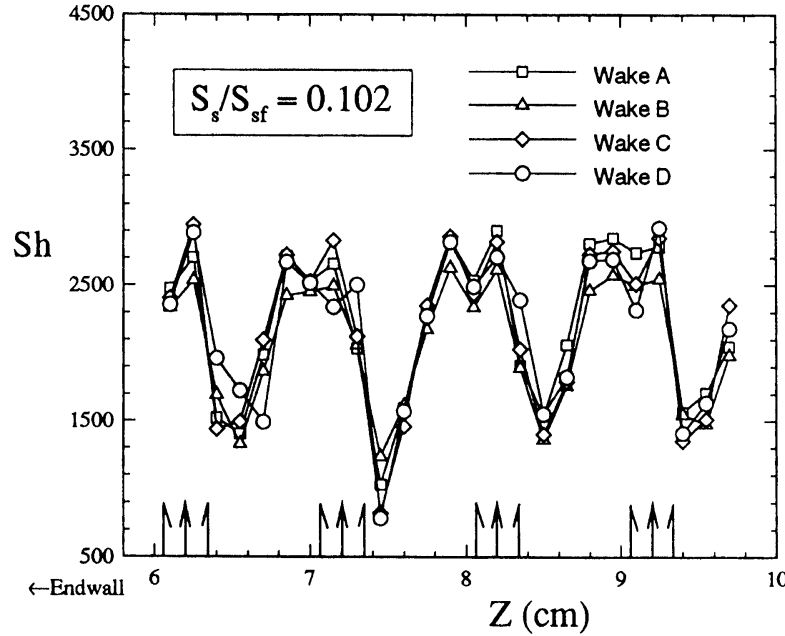

(b)

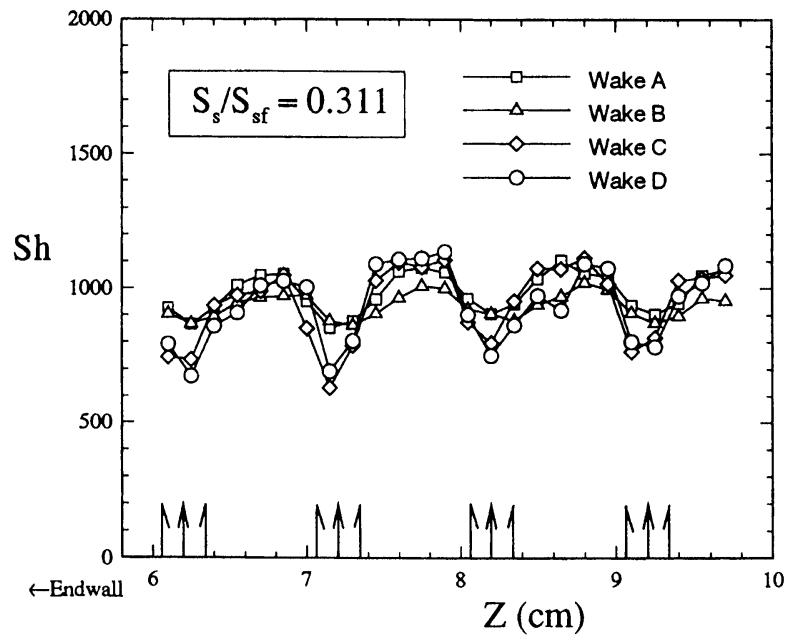

(d)

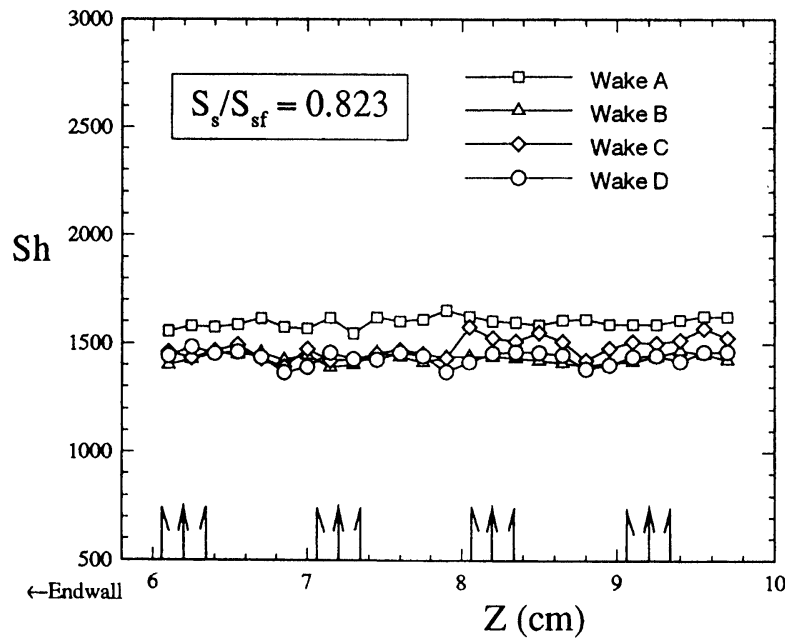

(f)

FIGURE 8 The spanwise distributions of $S h$ over the suction surface of the test blade at different distances for cases of wake A to wake D: (a) $S_{s} / S_{s f}=0.033$, (b) $S_{s} / S_{s f}=0.102$, (c) $S_{s} / S_{s f}=0.179$, (d) $S_{s} / S_{s f}=0.311$, (e) $S_{s} / S_{s f}=0.536$, and (f) $S_{s} / S_{s f}=0.823$. 


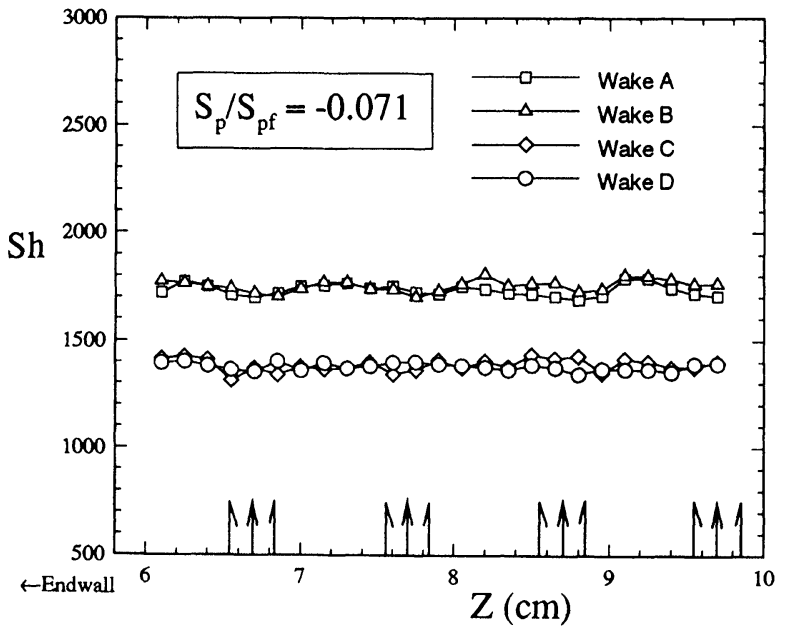

(a)

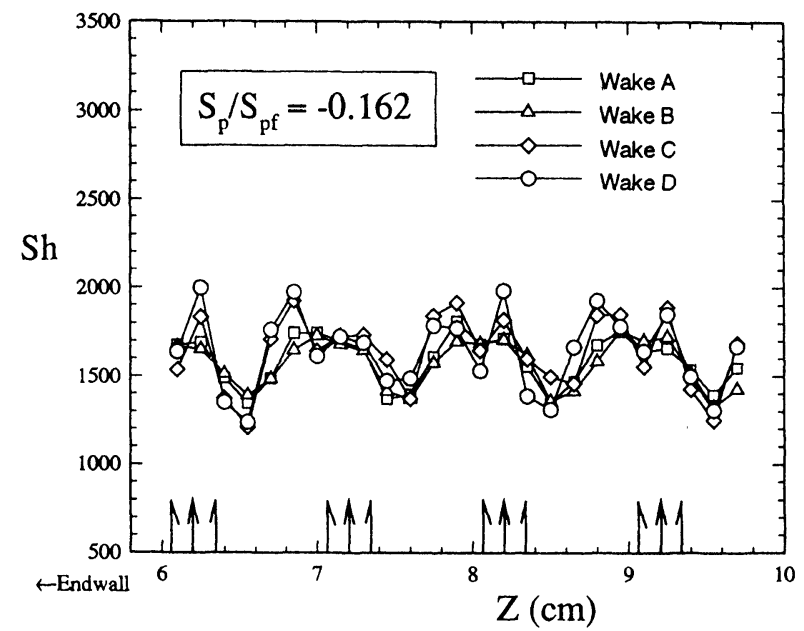

(c)

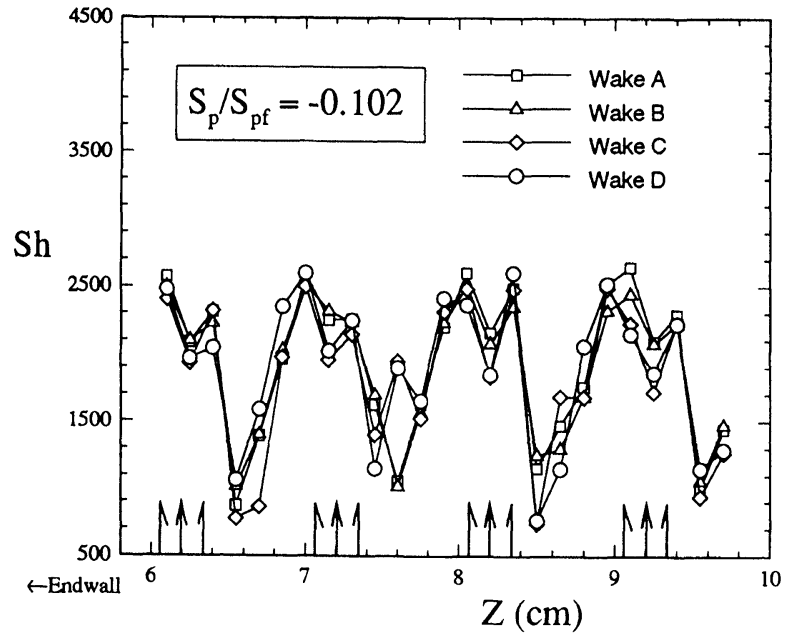

(b)

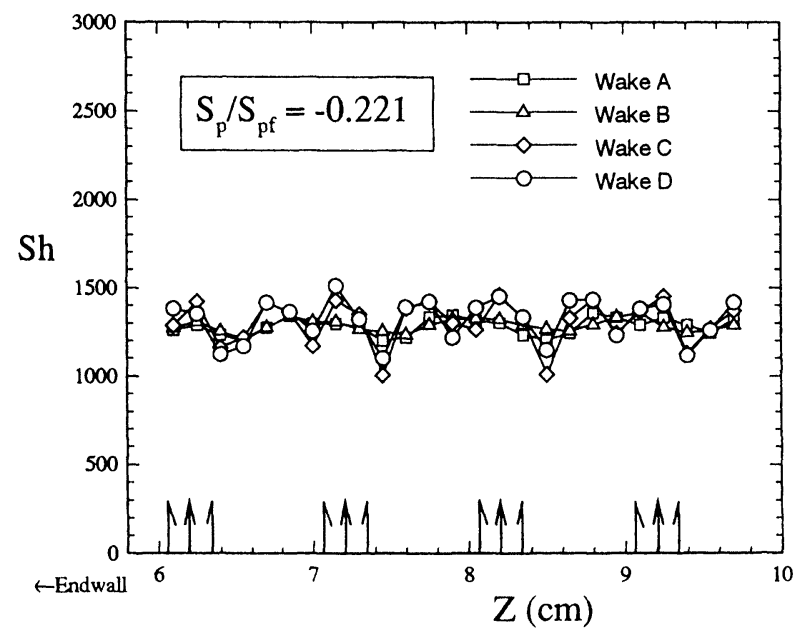

(d)

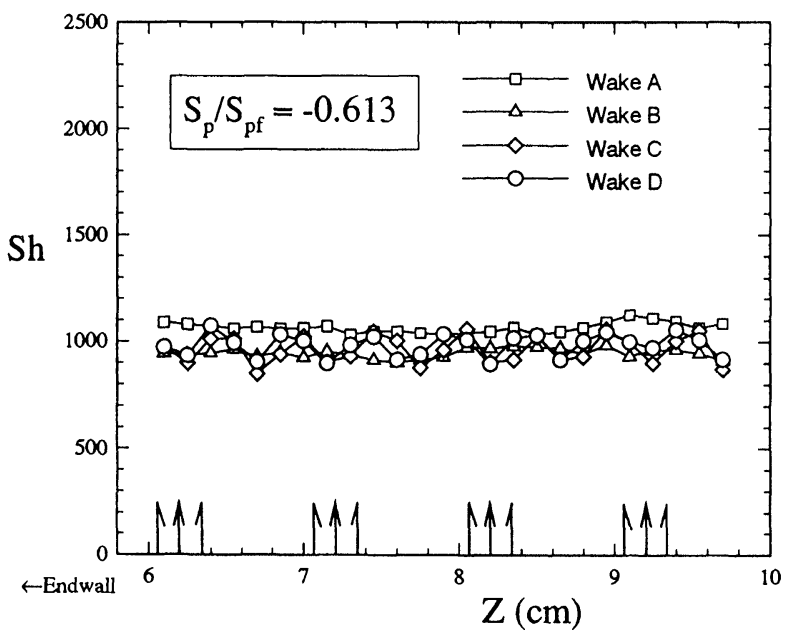

(e)

FIGURE 9 The spanwise distributions of $S h$ over the pressure surface of the test blade at different distances for cases of wake A to wake D: (a) $S_{p} / S_{p f}=-0.071$, (b) $S_{p} / S_{p f}=-0.102$, (c) $S_{p} / S_{p f}=-0.162$, (d) $S_{p} / S_{p f}=-0.221$, and (e) $S_{p} / S_{p f}=-0.613$. 
the injection row $P S$, is unexpectedly uniform (Fig. 9(a)). This fact may be due to the formation of recirculated flow between the injection rows $S L$ and $P S$. Again, twin peaks are observed in the local mass transfer distribution at $S_{p} / S_{p f}=-0.102$, probably as a result of the counterrotating vortices in the injection flows, as shown in Fig. 9(b). Downstream of injection row $P S$, the variation in the local mass transfer distribution is periodic and significant. The highest value of the local mass transfer rate can be four times as high as that of the minimum in $S h$. However, the spanwise variation in the local mass transfer reduces as the injection flows propagate downstream (Figures 9(b)- (e)). The twin-peak characteristic in the local mass rate still remains even at a location $S_{p} / S_{p f}=-0.613$ for both wake C and D, as shown in Fig. 9(e). However, the uniform distribution for $S h$ already appears for both wake A and B. This fact indicates a better mixing between injection jets with the boundarylayer flow on the pressure surface for the cases of wake $\mathrm{A}$ and $\mathrm{B}$ than that for the cases of wake $\mathrm{C}$ and $\mathrm{D}$.

\section{CONCLUSIONS}

A naphthalene sublimation technique was performed to investigate turbine blade mass transfer when the test turbine blade experiences both upstream wake and injection flows, which are ejected in the leading edge region of the blade. The measured results are presented to show the streamwise distribution of the spanwise-averaged turbine blade mass transfer and the spanwise distribution of the local mass transfer rate over both surfaces of the test blade at $R e_{2}=397,000, M=0.8$, and $T u=0.4 \%$. It can be observed that the injection flows result in a greater increase in turbine blade mass transfer than that for the upstream wake. With the presence of shower-head film cooling, the upstream wake has a more significant effect on mass transfer rate over the suction surface than that over the pressure side. The spanwise-averaged mass transfer rate is highest for the case of wake A probably because the leading edge of the turbine blade experiences the highest turbulence level among all four cases. Despite the fact that the spanwise-averaged turbine mass transfer is little affected by the variation in locations upstream wake generation, the spanwise mass transfer distributions downstream of injection holes are quite distinct for cases with the wake generation locations. Even with the presence of injection flows, a fairly uniform spanwise mass transfer distribution for the case of wake A is already observed at location $S_{s} / S_{s j}=0.536$ on the suction surface and location $S_{p} / S_{p f}=-0.221$ on the pressure surface which is not far from the turbine blade leading edge. The locations with uniform spanwise distribution in local mass transfer are closer to the leading edge for wake $\mathrm{A}$ and $\mathrm{B}$ than those for wake $\mathrm{C}$ and D. This fact indicates that the injection flows ejected from the injection holes mix more quickly with the boundary-layer flow on the blade surface for case of wake $\mathrm{A}$ and $\mathrm{B}$.

\section{Acknowledgments}

The authors would like to express their appreciation for the financial support by NSC in Taiwan under the Grant No. NSC-82-0401-D002-030.

\section{Nomenclature}

C chord length of the test blade, $=152.1 \mathrm{~mm}$

$d$ trailing edge diameter of the test blade, $=4.5 \mathrm{~mm}$

$D_{f} \quad$ diffusion coefficient of naphthalene into air

$h_{m} \quad$ local mass transfer coefficient, as determined from Eq. (2)

$L_{s b} \quad$ local sublimation depth of naphthalene during the exposure of test blade in an air-stream

$M \quad$ blowing ratio, as determined from Eq. (1)

$P \quad$ pitch of neighboring blades

$R e_{2} \quad$ exit Reynolds number, $=U_{2 e} C / v$

$S_{p} \quad$ pressure side curvilinear distance from the front stagnation line of the test blade

$S_{p f} \quad$ full length of pressure side curvilinear distance from the front stagnation line to the trailing edge, $=188 \mathrm{~mm}$

$S_{s} \quad$ suction side curvilinear distance from the front stagnation line of the test blade

$S_{s f} \quad$ full length of suction side curvilinear distance from the front stagnation line to the trailing edge, $=154 \mathrm{~mm}$ local Sherwood number, as determined from Eq. (3) spanwise-averaged Sherwood number turbulence level in the approaching mainstream, = $\sqrt{\overline{u^{\prime 2}}} / U_{x} \times 100 \%$

$U_{2 e} \quad$ exit velocity measured at the midspan of the blade cascade

$U_{\varkappa} \quad$ approaching mainstream velocity

$u^{\prime} \quad$ fluctuation of approaching mainstream velocity $Y \quad$ distance from the centerline of neighboring blades $Z \quad$ distance from the measuring point to the bottom endwall

\section{Injection Hole Rows}

SL row of injection holes that are located on the front stagnation line

$S P \quad$ row of injection holes that are located on the pressure side of test blade 
SS row of injection holes that are located on the suction side of test blade

\section{Greek Symbols}

$\Delta t \quad$ total time for the test blade being exposed in the airstream

$v \quad$ kinematic viscosity of air

$\rho_{s} \quad$ density of solid naphthalene

$\rho_{1 . \ldots} \quad$ local naphthalene vapor density on the test blade surface

$\rho_{2} \quad$ air density of the injection flows

$\rho_{\infty} \quad$ air density of the approaching mainstream

\section{References}

Abhari, R. S., and Epstein, A. H., 1994. An Experimental Study of Film Cooling in a Rotating Transonic Turbine, Journal of Turbomachinery, Vol. 116, pp. 63-70.

Camci, C., and Arts, T., 1990. An Experimental Convective Heat Transfer Investigation Around a Film-Cooled Gas Turbine Blade, Journal of Turbomachinery, Vol. 112, pp. 497-503.

Chen, P. H., and Miao, J. M., 1995. Mass Transfer over a Film-Cooled Turbine Blade, accepted for publication in International Journal of Rotating Machinerv.

Chen, P. H., Chen, J. J., Miao, J. M., Shou, S. F., and Liu, M., 1994a. The Effect of Upstream Conditions on the Convective Transport Phenomena over a Turbine Blade, in Heat Transfer in Gas Turbine, ASME HTD-Vol. 300, pp. 31-44.

Chen, P. H., Miao, J. M., and Chen, J. W., 1994b. Convective Transport Phenomena for Stagnation Film Cooling, in Heat Transfer in Gas Turbine, ASME HTD-Vol. 300, pp. 55-62.

Cho H. H., Jabbari M. Y., and Goldstein R. J., 1994. Mass Transfer With Flow Through an Array of Rectangular Cylinders, Journal of Heat Transfer, Vol. 104, pp. 911-918.

Dunn, M. G., Kim, J., Civinskas, K. C., and Boyle, R. J., 1994. Time-Averaged Heat Transfer and Pressure Measurements and Com- parison With Prediction for a Two-Stage Turbine, Journal of Turbomachinery, Vol. 116, pp. 14-22.

Dunn, M. G., Seymour, P. J., Woodward, S. H., George, W. K., and Chupp, R. E., 1989. Phase-Resolved Heat-Flux Measurements on the Blade of a Full-Scale Rotating Turbine, Journal of Turbomachinery, Vol. 111, pp. 8-19.

Goldstein, R. J., Wang, H. P., and Jabbari, M. Y., 1995. The Influence of Secondary Flows Near the Endwall and Boundary-Layer Disturbance on Convective Transport from a Turbine Blade, ASME Paper No. 95-GT-165.

Karni, J., and Goldstein, R. J., 1990. Surface Injection Effect on Mass Transfer from a Cylinder in Crossflow: A Simulation of Film Cooling in the Leading Edge Region of a Turbine Blade, Journal of Turbomachinery, Vol. 112, pp. 418-427.

Kline, S. J., and McMClintock, F. A., 1953. Describing Uncertainties in Single Sample Experiments, Journal of Mechanical Engineering, Vol. 75, pp. 3-8.

Kruse, H., 1985. Effects of Hole Geometry, Wall Curvature and Pressure Gradient on Film Cooling Downstream of a Single Row, in AGARD CP-390.

Magari, P. J., and LaGraff, L. E., 1994. Wake-Induced Unsteady Stagnation-Region Heat Transfer Measurements, Journal of Turbomachinery, Vol. 116, pp. 29-38.

Mayle, R. E., and Dullenkopf, K., 1990. A Theory for Wake-Induced Transition, Journal of Turbomachinery, Vol. 112, pp. 188-195.

Mehendale, A. B., Han, J.-C., Ou, S., and Lee, C. P., 1994. Unsteady Wake Over a Linear Turbine Blade Cascade With Air and $\mathrm{CO}_{2}$ Film Injection: Part II-Effect on Film Effectiveness and Heat Transfer Distributions, Journal of Turbomachinery, Vol. 116, pp. 730-737.

Ou, S., and Han, J. C., 1994. Leading Edge Film Cooling Heat Transfer Through One Row of Inclined Film Slots and Holes Including Mainstream Turbulence Effects, Journal of Heat Transfer, Vol. 116, pp. 561-569.

Ou, S., Han, J.-C., Mehendale, A. B., and Lee, C. P., 1994. Unsteady Wake Over a Linear Turbine Blade Cascade With Air and $\mathrm{CO}_{2}$ Film Injection: Part I-Effect on Heat Transfer Coefficients, Journal of Turbomachinery, Vol. 116, pp. 721-729. 

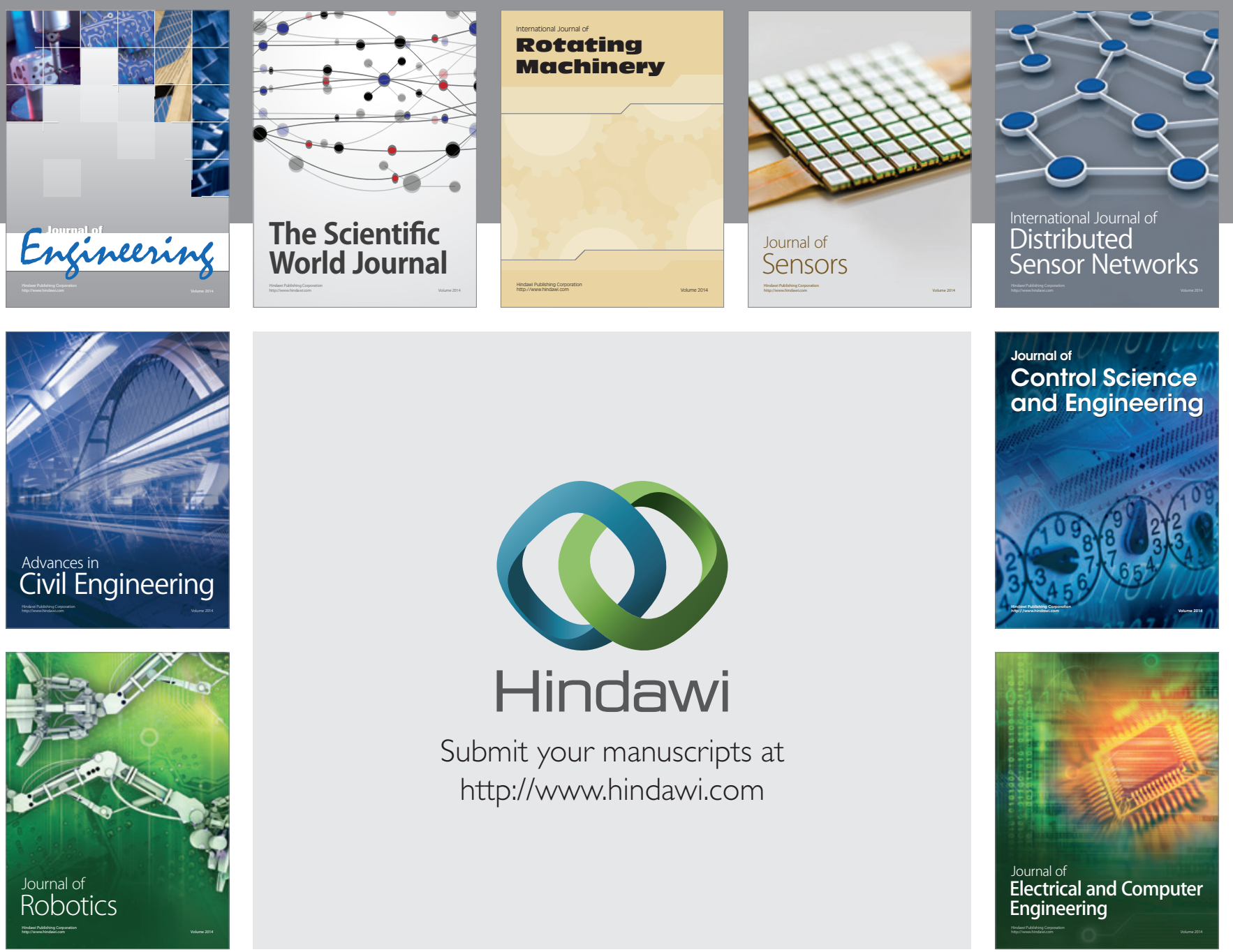

Submit your manuscripts at

http://www.hindawi.com
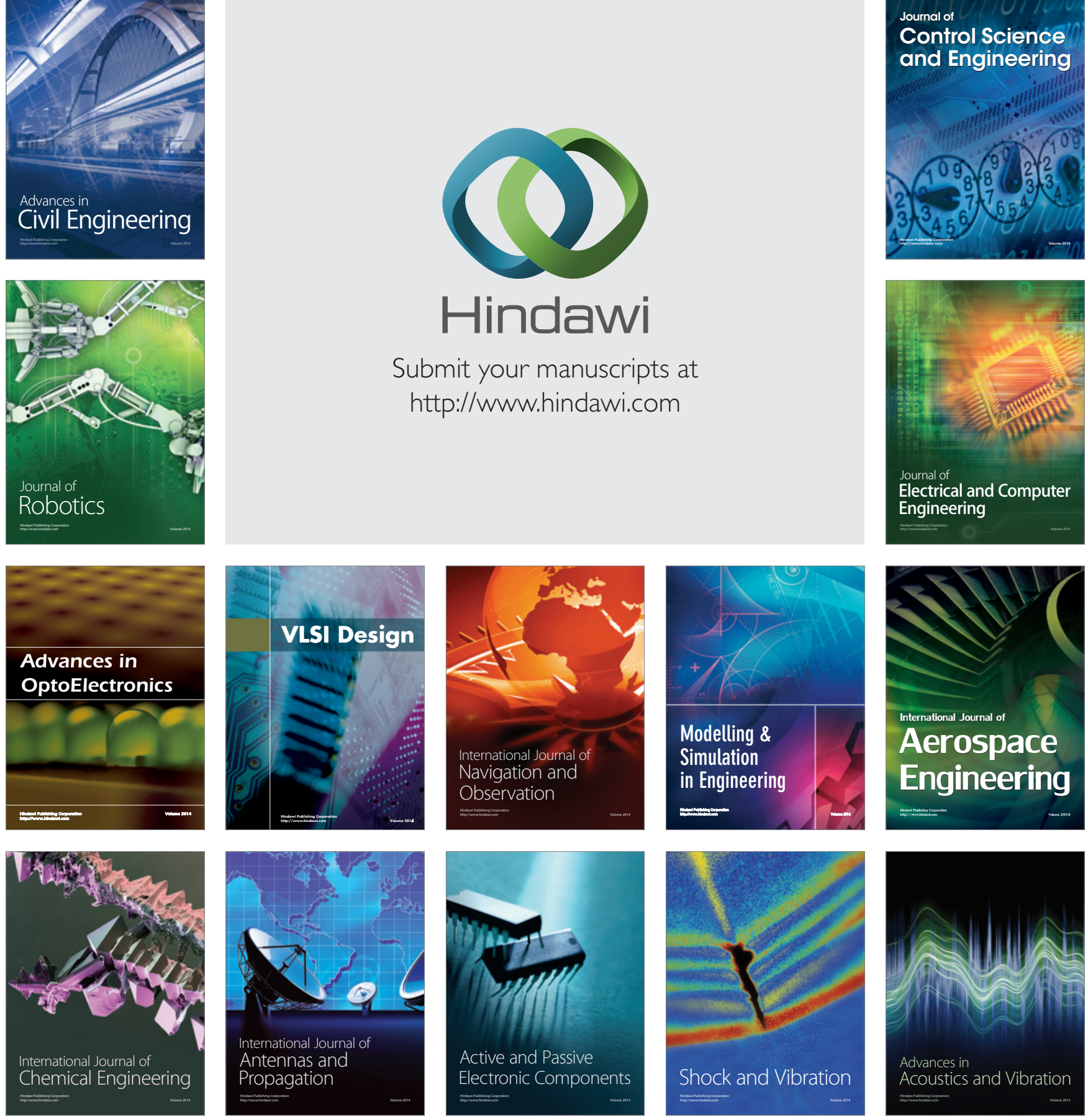